\title{
Clinical Update: Eating Disorders in Children and Young People
}

\author{
Helen Bould, Claudia Newbegin, Anne Stewart, Alan Stein, Mina Fazel
}

\section{$\underline{\text { Introduction }}$}

Eating disorders (ED) are a group of conditions in which negative beliefs about eating, body shape and weight accompany behaviours including restricting eating, binge eating, excessive exercise, vomiting and laxative use. In Anorexia Nervosa (AN), weight is "less than minimally expected", dietary intake is restricted, and there are disturbances in the way weight and shape are experienced. Bulimia Nervosa (BN) comprises binge eating with compensatory behaviours aimed at reducing weight, such as vomiting or excessive exercise, while Binge Eating Disorder (BED) includes binge eating but without compensatory behaviours. In DSM-5", a new category “Other Specified Feeding or Eating Disorder" (OSFED) replaces EDNOS (Eating Disorder Not Otherwise Specified) for ED causing distress and impairment but not meeting full criteria for other diagnoses. Binge Eating Disorder (BED) has now been included and it is anticipated that ICD-11 criteria will be broad criteria consistent with DSM changes. ${ }^{2}$

Eating disorders (ED) are associated with high mortality: a meta-analysis found that in patients with AN, rates of death are 5.9 times higher than would be expected in an age and sex matched population, and in patients with BN and other eating disorders, rates are 1.9 times higher. ${ }^{3}$ ED are relatively common amongst adolescents girls: a recent Dutch community study using new (broader) DSM-5 criteria found a lifetime prevalence among 19 year old women of $5.7 \%$ compared to $1.2 \%$ in males, with Binge Eating Disorder the most common (see Table). ${ }^{4}$ Incidence rates of ED in UK primary care increased from 32.3 per 100,000 in 2000 to 37.2 in $2009 .{ }^{5}$ While there are few prevalence studies in low and middle income countries, the Global Burden of Disease Study notes that eating disorders do occur across the world. ${ }^{6}$ Population studies consistently find that many people meeting diagnostic criteria do not receive any kind of treatment (around $56 \%$ in Holland ${ }^{4}$; $28 \%$ in the US ${ }^{7}$ ); those with AN are more likely to receive treatment. The UK Chief Medical Officer's Annual Report ${ }^{8}$ highlights the importance of early intervention (beginning NICE recommended treatment as early as possible in the course of the illness) for better treatment response; for example, outcomes in AN are poor if the patient does not receive effective treatment within the first three years. ${ }^{910}$ This update will present a structured approach to diagnosis and management of children and young people with eating disorders, including risk assessment and when to refer, following recommendations in the May 2017 updated NICE guideline. ${ }^{11}$. 
Table 1: Lifetime Prevalence of Eating Disorders in 19-20 year olds

\begin{tabular}{|l|l|l|}
\hline Eating Disorder & \multicolumn{2}{|l|}{ Lifetime Prevalence (\%) in 19-20 year olds } \\
\hline & Women & Men \\
\hline Anorexia Nervosa & 1.7 & 0.1 \\
\hline Bulimia Nervosa & 0.8 & 0.1 \\
\hline Binge eating disorder & 2.3 & 0.7 \\
\hline $\begin{array}{l}\text { Other Specified Feeding or } \\
\text { Eating Disorder }\end{array}$ & 0.6 & 0.3 \\
\hline $\begin{array}{l}\text { Unspecified Feeding or Eating } \\
\text { Disorder }\end{array}$ & 0.2 & 0 \\
\hline Any Eating Disorder & 5.7 & 1.2 \\
\hline
\end{tabular}

\section{What are the Risk Factors?}

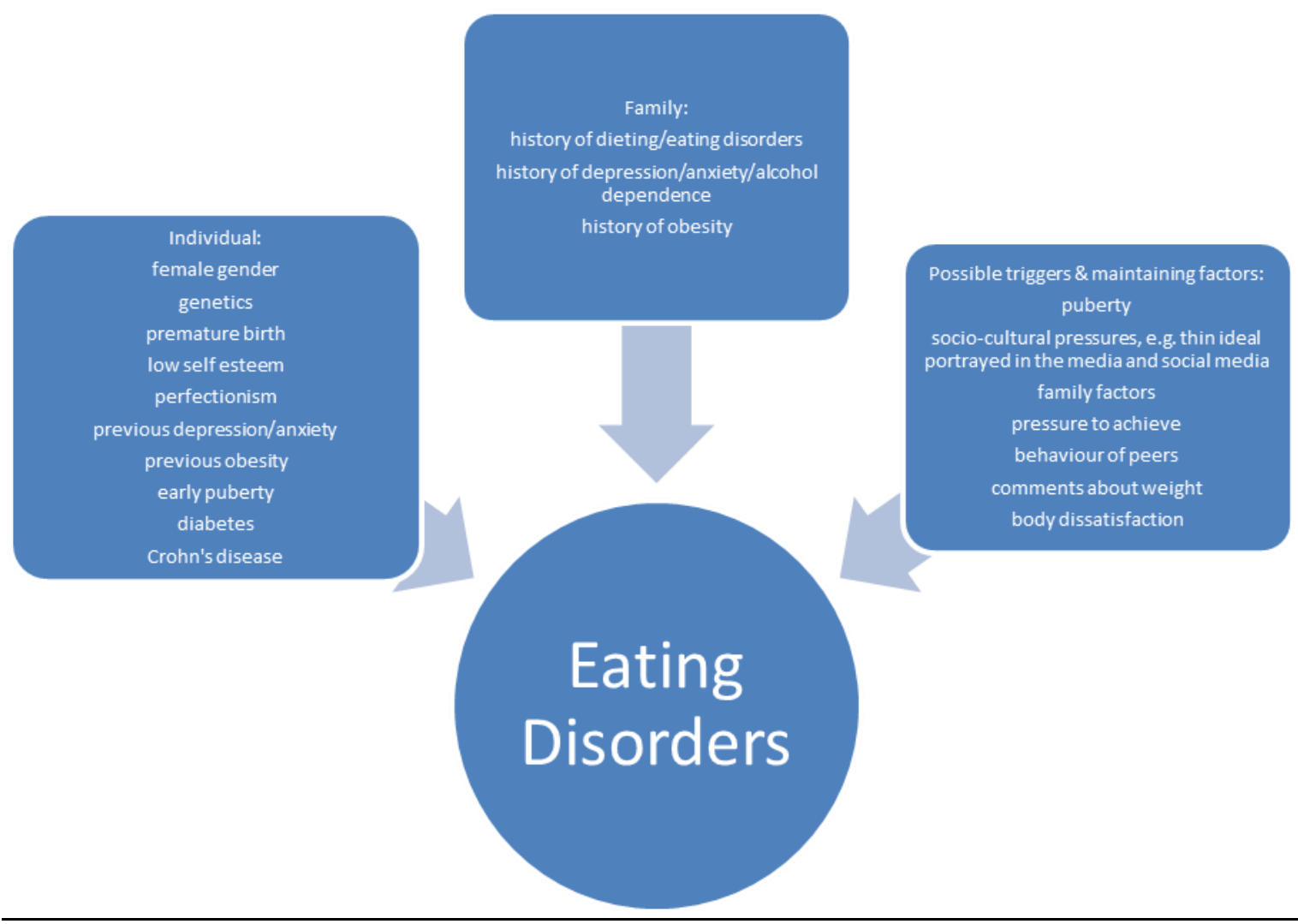




\section{How are they diagnosed?}

Diagnoses are made on clinical history corresponding to ICD-10/DSM-5 criteria. ${ }^{1}$ Clinicians should consider a possible eating disorder and ask further pertinent questions (see associated Practice Pointer) in patients presenting with a change in weight (increase, decrease or failure to keep in line with growth), erratic eating (skipping meals or binge eating), preoccupation with shape or weight, vomiting, low mood or withdrawal from friends and family, periods stopping or if complaining of feeling cold.

\section{Differential Diagnoses \& Comorbidities}

In the case of weight loss, the differential includes diabetes, hyperthyroidism, coeliac disease and malignancies, and the primary care physician should screen for these on history, examination and investigations as detailed below. Eating disorders are associated with increased rates of other mental disorders, including depression, ${ }^{12}{ }^{13}$ anxiety, ${ }^{1314} \mathrm{OCD}^{13-15}$ and alcohol misuse/dependence. ${ }^{1315}$ ${ }^{16} \mathrm{~A}$ large Finnish patient cohort found that diabetes was associated with higher subsequent rates of $A N, B N$ and BED, and that Crohn's disease was associated with higher subsequent rates of AN compared with controls. ${ }^{17}$

\section{What are the psychological and physical complications?}

Psychological - Low weight can cause significant psychological consequences such as low mood, suicidal ideation and behaviour, low self-esteem, irritability, increased anxiety, social withdrawal and rigidity of thinking, ${ }^{18}$ all of which can contribute to further weight loss. These symptoms can impact on relationships with others. Overvaluation of shape and weight may alter a young person's value system, and identity, with a focus on weight and what is eaten, rather than other aspects of life. This, alongside, problems with concentration and decision making, can impair capacity to consent to treatment.

Physical - Chronic under-nourishment can lead to disruption of all major organ systems. ${ }^{19} 20$ Rapid weight loss may be particularly damaging as the body has less time to adapt. ${ }^{21}$ The cardiovascular system responds to a low basal metabolic rate in underweight patients with a decreased heart rate and blood pressure, ${ }^{21}$ autonomic dysregulation, postural hypotension, postural tachycardia ${ }^{22}$ and increased risk of syncope..$^{21}$ Both hypokalaemia, and low weight in the absence of hypokalaemia, can lead to prolonged QTc, which can in turn lead to ventricular arrhythmias and sudden death. ${ }^{23}$ Hypocalcaemia and hypomagnesaemia are less common but also contribute to arrhythmias. ${ }^{21}$ There is evidence for effects on the brain, where a reduction in grey and white matter volume has been observed in patients with anorexia nervosa. ${ }^{20}$

Physical consequences of purging include mechanical damage from self-induced vomiting, or indirectly via electrolyte imbalance. Gastritis or gastro-oesophageal reflux disease can be present in all ED, particularly if there is vomiting, ${ }^{22}$ and Mallory-Weiss tears may occur. Very rarely, malnutrition can lead to pancreatitis. ${ }^{21} \mathrm{Gl}$ bleeding can lead to anaemia; malnutrition can cause neutropaenia and anaemia, as a result of impaired bone marrow function.

Amenorrhoea is no longer in the diagnostic criteria for AN in DSM 5, but remains a common feature, probably due to hypothalamic-pituitary-ovarian dysfunction, which may be partly the result of decreased leptin and increased ghrelin levels. ${ }^{2425}$ 
Decreased Bone Mineral Density is common in AN, and can be due to malnutrition or low BMI as well as amenorrhoea. ${ }^{24}$ Patients with AN are almost twice as likely to have a bone fracture as healthy controls. ${ }^{26}$

Chronic malnutrition leads to muscle wasting and weakness ${ }^{10}$ which can result in a low creatinine levels. ${ }^{21}$ Conversely, dehydration (due to starvation or diuretic abuse) or muscle breakdown can lead to raised creatinine levels. Over-hydration with calorie-free fluids, to feel "full" without eating, or before being weighed so that weight appears to be stable or increasing, can lead to hyponatraemia with associated risk of seizures.

\section{What investigations should you do?}

See table below; the purpose of the investigations is to assess for physical complications so that they can be managed appropriately, and to exclude other possible causes of weight loss or gain.

\section{$\underline{\text { Risk Assessment }}$}

Risk assessment helps inform immediate and long-term treatment decisions. Features of high physical risk which may indicate a need for inpatient medical admission ${ }^{21}$ are detailed in the Examination and Investigations tables below. Readers are encouraged to refer to the Junior MARSIPAN guidelines ${ }^{21}$ (see Box below) for detailed guidance on managing very ill patients with anorexia nervosa.

Full psychiatric assessment, including of suicidal thoughts and plans, is important as people with AN are at higher risk of suicide than the general population. ${ }^{3}$ Psychiatric comorbidities in AN are common and associated with higher mortality ${ }^{327}$ and worse treatment outcomes. ${ }^{3}$ Full psychiatric assessment, including of suicidal thoughts and plans, is important.

\section{What are the treatments?}

Intervening early is associated with better treatment outcomes. ${ }^{910} \mathrm{~A}$ holistic approach should be taken, potentially including a number of modes of treatment, and it is important that the primary care team is kept informed about progress in secondary care, and is invited to attend key reviews, especially towards the end of treatment to ensure a safe transition back to primary care. Principles of managing eating disorders that families might find helpful include: strengthening family relationships away from the pressures of food, and focusing on enjoyable activities together; conceptualising eating problems as separate from the young person, so that parent and child can "team up" against the disorder; eating regular, balanced meals as a family where possible; avoiding regular weighing and other forms of body checking as these can increase concerns about weight and shape. Specific types of treatment can include:

\section{- Psychological Therapies:}

- AN

- Family-Based Treatment, or "Anorexia-Nervosa-Focused Family Therapy"28 is recommended by NICE as the first line treatment for AN in children and young people. ${ }^{11}$. With 12 RCT's (1060 participants in total) supporting its efficacy, it is regarded as the core treatment for AN in children and young people. ${ }^{1929}$ It emphasises the importance of parents initially taking 
responsibility for refeeding, before gradually handing back responsibility to the young person. This is best done in an atmosphere of collaboration and minimisation of blame, for which support from the clinical team is often required.

- There is moderate evidence for Family System Therapy ${ }^{19}$, Adolescent Focussed Therapy ${ }^{19}$ and Cognitive Behavioural Therapy - Enhanced (CBT-E) (an enhanced, transdiagnostic version of the original CBT developed for bulimia nervosa). ${ }^{19}$ NICE guidance recommends CBT-E if Family Therapy as described above is contraindicated, unacceptable or ineffective.

BN: A recent review concluded that there is a weaker evidence-base for BN treatment in children and young people, ${ }^{29}$ but

- In adolescents, one RCT found Family Therapy for BN to be more effective than supportive individual therapy ${ }^{30}-$ and this is what the NICE guideline recommends ${ }^{11}$

- RCT's finding CBT-E to be effective for BN have included high proportions of young adults, ${ }^{31}$ so it may be reasonable to generalise from these. ${ }^{32}$ NICE suggests CBT-E be used when Family Therapy is ineffective, contraindicated or unacceptable.

- One RCT suggests that CBT-guided self-help may be more effective than Family-Based Treatment (adapted for this study for use in BN), ${ }^{33}$ as well as being more cost efficient and acceptable to patients.

- Psychotropic Medications: are not recommended for the treatment of AN in primary care. A meta-analysis found no difference between placebo and either antidepressant or antipsychotic medication on weight gain in $\mathrm{AN}^{,}{ }^{34}$ and no differences in $\mathrm{AN}$ symptomatology between antipsychotics and placebo. ${ }^{35}$ This may be due to the RCT's being underpowered, but in view of drug safety considerations around the use of antidepressants in adolescents, and the risk of prolonged QT interval in both low weight individuals and for those taking antipsychotics, ${ }^{36}$ they should be used cautiously if needed for treatment of co-morbid depression or anxiety, and only by ED specialists with regular monitoring.

There is very little evidence for pharmacotherapy in young people with BN, but high dose antidepressants improve outcomes in adults with $\mathrm{BN}^{37-39}$ so fluoxetine may be considered by specialist services, if other treatments are not working.

- Weight restoration: For underweight individuals, re-establishing a healthy weight is considered by experts to be a key part of treatment (NICE), although psychological treatment is crucial to ensure a full recovery. ${ }^{40}$ Regular monitoring of electrolytes, phosphate and magnesium is advised due to the risk of refeeding syndrome, ${ }^{1921}$ when there has been rapid weight loss and a period of minimal food intake. Monitoring should be undertaken in specialist care; according to local protocols this may be by the specialist eating disorder team or the paediatricians. Recommended rates of weight regain range from $500 \mathrm{~g}$ to $1400 \mathrm{~g}$ per week, ${ }^{22}{ }^{41}$ depending on the setting; a recent $\mathrm{RCT}$ in young people found commencing refeeding with $1200 \mathrm{kcal} /$ day vs $500 \mathrm{kcal} /$ day did not increase rate of refeeding syndrome. ${ }^{42}$ Expert advice suggests offering paediatric supplement feeds (high-calorie drinks) if young people struggle to complete meals; ${ }^{21}$ in 
hospital settings feeding via a nasogastric tube can be considered in cases where weight is very low and if meals cannot be completed. ${ }^{21}$

- Vitamin /mineral supplements: Experts are divided as to whether refeeding in high risk underweight patients should include routine supplementation with thiamine and phosphate. ${ }^{1921}$ A multivitamin and mineral supplement is usually recommended. ${ }^{21}$

- Oestrogen-replacement therapy: Transdermal oestrogen application is partially effective in increasing bone density, although should only be initiated by an appropriate specialist. ${ }^{25}$ Oral oestrogen does not increase bone density in young people and is not recommended. The most effective way of improving bone density is via regaining a healthy weight and re-establishing menstruation. ${ }^{25}$

- Legal framework: Most jurisdictions acknowledge that serious or life threatening eating disorders can be treated compulsorily with refeeding, under the relevant legal framework, when the patient is not able to consent to treatment. Some younger adolescents may respond to a firm approach from parents with regard to participating in treatment, but if they are resistant and the illness is sufficiently serious then the use of a formal legal framework helps to safeguard their rights and well-being.

\section{When to admit: Inpatient vs Outpatient treatment}

Practice guidelines ${ }^{22} 41$ advise that most patients with ED can be treated as outpatients, with specialist local services being associated with lower rates of admission, and more consistent care; ${ }^{43}$ inpatient or day patient services may be needed in more severe cases or if the patient does not improve with outpatient care. ${ }^{19}$ Inpatient treatment in a medical or paediatric ward is necessary where there is high medical risk (see Boxes on Examination and Investigations). ${ }^{11} \mathrm{~A}$ systematic review concluded that there is preliminary support for treating young people with AN in outpatient settings: outcomes are equivalent for brief inpatient treatment followed by outpatient care compared to prolonged inpatient care; specialist outpatient care is more cost efficient. ${ }^{44}$ Transitions are particularly important in ED as there needs to be careful multidisciplinary planning between primary care, paediatric, medical and psychiatric settings, between in and out-patient treatment, and between child and adolescent and adult services in order to ensure continuity of care and minimisation of risk..$^{21} 45$

\section{Box: Can ED be prevented?}

A systematic review ${ }^{46}$ found that both universal and targeted prevention programmes, the majority of which focus on psychoeducation, produce moderate effects on knowledge but have little effect on reducing ED pathology. A recent RCT has found a reduction in concerns about weight and shape 12 months after a universal school-based intervention in 13 year olds. ${ }^{47}$

\section{Box: "Sources and Selection Criteria"}

We used personal archives of references and consulted the Cochrane Collaboration database and the BMJ Clinical Evidence website using the search terms "eating disorder", "anorexia nervosa", "bulimia nervosa", "OFSED", "EDNOS". 
- Eating disorders have relatively high mortality and associated morbidity (due to physical health, psychological consequences, and suicide)

- Early intervention improves prognosis so patients with suspected eating disorders should be referred promptly to specialist services, with results of preliminary tests as detailed in the Investigations box

- Primary care physicians are key in keeping an overview of the holistic management of both physical and psychological health, which is key to successful treatment

- Consider eating disorders in patients presenting with unexpected changes in weight, either increasing, decreasing, or failing to keep in line with growth

\section{Box: Patient perspective (by a recovered patient)}

GPs need to know:

- $\quad$ that patients should be informed that even if they look and feel well and are of normal weight they can actually still be very unwell

- $\quad$ that female patients may find it easier to talk to a female doctor about body image problems; offering patients a choice of who to see is helpful.

- $\quad$ that it's important to speak to the patient on their own - without their parents

- $\quad$ that patients should be given the same respect that you would give to adults, and have their problems taken seriously

that social media can often be a massive factor in their illness

that even though patients may find it distressing, hard facts about the physical risks are essential: the patient may respect the information given by a doctor more than that from their parents/families

\section{Box: Questions for future research}

- "Which factors influence the duration of recovery and the possibility of complete recovery?" was the top question from the recent James Lind Alliance priority setting process involving patients, carers and clinicians. ${ }^{48}$

- Medication: Experts suggest more research is needed into antipsychotic use in AN. ${ }^{19}$ Tumour necrosis factor dronabinol, and ghrelin agonists and antagonists are also being investigated at present. ${ }^{19}$

- Psychotherapy: studies of CBT-E in young people with AN are ongoing; feasibility and open studies of Multi-Family Therapy for AN are promising.

\section{Box: Additional Educational Resources}

All the websites listed are free; none require registration. 
- The Royal College of Psychiatrists website includes readable, user-friendly, evidence-based information

[http://www.rcpsych.ac.uk/healthadvice/problemsdisorders/anorexiaandbulimia.aspx]

- Junior MARSIPAN (Management of Really Sick Patients under 18 with Anorexia Nervosa) guidelines for identifying and managing high risk patients with AN.

(http://www.rcpsych.ac.uk/usefulresources/publications/collegereports/cr/cr168.aspx)

- $\quad$ NICE Guidelines for Eating Disorders https://www.nice.org.uk/guidance/cg9

- B-EAT, the UK's leading charity supporting anyone affected by eating disorders has a section for professionals: https://www.b-eat.co.uk/for-professionals

- Royal Australian and New Zealand College of Psychiatrists have recently updated practice guidelines: https://www.ranzcp.org/Files/Resources/Publications/CPG/Clinician/EatingDisorders-CPG.aspx

\section{Box: Information Resources for Patients}

All the websites listed are free; none require registration.

- B-EAT - the UK's leading charity supporting anyone affected by eating disorders https://www.b-eat.co.uk offers information, helplines, online and peer support groups for patients with eating disorders, their families and friends

- www.maudsleyparents.org - Maudsley Parents, a website for parents of children with eating disorders

- http://www.feast-ed.org - an international organization of and for parents and caregivers to help loved ones recover from eating disorders by providing information and mutual support

- http://www.anorexiabulimiacare.org.uk - a UK eating disorders organisation with over 25 years of experience

- www.healthtalk.org - a useful resource on many disorders, this site has information on young people's experiences of eating disorders and the range of interventions (http://www.healthtalk.org/young-peoples-experiences/eating-disorders/topics )

Practical Box 1. When to refer (and what you can do whilst awaiting referral)

Experts advise that all young people with a probable eating disorder be referred to local specialist mental health services for children and young people, with results of the tests detailed in the Investigations box. Early discussion with services is good practice if unsure about referral. ${ }^{21}$ Recent guidance in England recommends that all under 18's start evidence-based treatment within four weeks. ${ }^{49}$ Where local services do not exist, or do not meet this standard, and whilst the young person is waiting to be seen, family doctors could provide information to the family and offer weekly weigh-in and routine investigations and support as indicated by clinical presentation to monitor in case of deterioration. ${ }^{21}$

Indications for urgent referral to specialist mental health services for children and young people include rapid weight loss, $\mathrm{BMI}<75 \%$ of expected body weight, and binge eating and purging multiple times a day. Indications for referral for emergency paediatric assessment include pulse $<50 \mathrm{bpm}$, arrhythmia, or postural tachycardia $>20 \mathrm{bpm}$; BP $<80 / 50 \mathrm{mmHg}$ or postural drop $>20 \mathrm{mmHg}$; temperature <35.5C; QTc >450ms; significant hypokalaemia; significant neutropaenia. ${ }^{19}$ 
In such cases, simultaneous referral to both paediatrics and mental health services is recommended. ${ }^{21}$

\section{Box: "Education into Practice"}

1) Were you aware of the changes in diagnostic criteria for eating disorders and have you been using these in your clinical practice?

2) Do you know how to access specialist services for people with suspected eating disorders in your local area?

3) What advice might you give to parents who are concerned their child is at risk of developing an eating disorder?

4) Did you know that providing early intervention within a specialist service is the most important way to improve outcomes in eating disorders? ${ }^{43}$

Box: How patients were involved in creating the article

A recovered patient, and the parents of two young people with an eating disorder, who wished to remain anonymous, read drafts of the article and made valuable suggestions which we have incorporated here.

Box: Examination (Readers are also directed to the more detailed tables in the Junior MARSIPAN guidelines ${ }^{21}$ )

\begin{tabular}{|c|c|c|}
\hline Examination & Possible Features & $\begin{array}{l}\text { Features Suggestive of High Medical Risk } \\
\text { (consider medical admission) }\end{array}$ \\
\hline General observations & $\begin{array}{l}\text { - } \text { - May appear totally well } \\
\text { - } \quad \text { Lanugo hair } \\
\text { - } \quad \text { Russell's sign (callous on back of } \\
\text { hand) suggests self-induced } \\
\text { vomiting } \\
\text { - Tooth decay and parotid gland } \\
\text { - } \text { swelling (in vomiting) } \\
\text { - Indicators of another cause of } \\
\text { - underweight: pallor, thyroid } \\
\text { signs, organomegaly } \\
\text { Dehydration can be difficult to } \\
\text { detect }\end{array}$ & \\
\hline
\end{tabular}




\begin{tabular}{|c|c|c|}
\hline Examination & Possible Features & $\begin{array}{l}\text { Features Suggestive of High Medical Risk } \\
\text { (consider medical admission) }\end{array}$ \\
\hline $\begin{array}{l}\text { Pulse, Temperature } \\
\text { and Blood Pressure }\end{array}$ & $\begin{array}{l}\text { Decreased basal metabolic rate in } \\
\text { starvation leads to } \\
\text { - decreased core temperature } \\
\text { - slowed pulse } \\
\text { - low blood pressure }\left(<2^{\text {nd }} \text { centile }\right)\end{array}$ & $\begin{array}{l}\text { - } \text { Pulse }<50 \text { bpm } \\
\text { - } \text { Low } \mathrm{BP}\left(<0.4^{\text {th }} \text { centile) }\right. \\
\text { - } \text { Postural hypotension (drop } \geq \\
15 \mathrm{~mm} \mathrm{Hg}) \\
\text { - } \quad \text { Postural tachycardia (increase }>20 \\
\text { bpm) } \\
\text { - } \text { Delayed capillary refill } \\
\text { - } \text { Temperature }<35.5\end{array}$ \\
\hline $\begin{array}{l}\text { Height and Weight } \\
\text { (BMI) }\end{array}$ & $\begin{array}{l}\text { Percentage BMI should be } \\
\text { calculated as (Actual BMI } \\
\text { x100)/Median BMI ( } 50^{\text {th }} \text { centile) } \\
\text { for age and gender } \\
\text { - Normal/increased BMI } \\
\text { (BN/OFSED) } \\
\text { - Weight 'less than minimally } \\
\text { expected' for height in AN }\end{array}$ & $\begin{array}{l}\text { Weight }<75 \% \text { of expected } \\
\text { (although note that weight for } \\
\text { height is a poor proxy for medical } \\
\text { instability) } \\
\text { - Rapid weight loss }(0.5-1 \mathrm{~kg} / \text { week) }\end{array}$ \\
\hline $\begin{array}{l}\text { Musculoskeletal } \\
\text { system including the } \\
\text { 'Sit-up' and 'Squat- } \\
\text { stand' tests }\end{array}$ & $\begin{array}{l}\text { Muscle weakness is common in } \\
\text { underweight } \\
\text { - Patient may be unable to sit up } \\
\text { from lying or to rise from a squat } \\
\text { position } \\
\text { - Back or bone pain from spinal } \\
\text { compression or osteoporotic } \\
\text { fractures }\end{array}$ & $\begin{array}{l}\text { - Spinal compression or osteoporotic } \\
\text { fractures }\end{array}$ \\
\hline Abdomen & $\begin{array}{l}\text { - Tenderness/bloating due to } \\
\text { gastritis (most often if vomiting) } \\
\text { - Constipation or ileus }\end{array}$ & - Gastric dilatation \\
\hline
\end{tabular}


Box: Investigations (Note that these are often normal, even in acutely unwell patients.)

\begin{tabular}{|c|c|c|}
\hline Investigation & Possible Features* & $\begin{array}{l}\text { Features Suggestive of High Medical } \\
\text { Risk (consider medical admission) }\end{array}$ \\
\hline Full Blood Count & $\begin{array}{l}\text { Anaemia (rare; possible causes: GI } \\
\text { bleeding/malnutrition); neutropaenia } \\
\text { (which is associated with increased risk of } \\
\text { refeeding syndrome); } \\
\text { thrombocytopaenia }\end{array}$ & Significant neutropaenia \\
\hline $\begin{array}{l}\text { Urea and } \\
\text { electrolytes }\end{array}$ & $\begin{array}{l}\text { Electrolyte disturbance (vomiting/ } \\
\text { laxative or diuretic abuse/overhydration) } \\
\text { Dehydration (vomiting, diuretics, } \\
\text { starvation) }\end{array}$ & $\begin{array}{l}\text { Hyponatraemia } \\
\text { Hypokalaemia }\end{array}$ \\
\hline $\begin{array}{l}\text { Calcium, } \\
\text { Magnesium and } \\
\text { Phosphate }\end{array}$ & Low (malnourished) & $\begin{array}{l}\text { Hypophosphataemia (this can also } \\
\text { occur in the context of refeeding) }\end{array}$ \\
\hline $\begin{array}{l}\text { Erythrocyte } \\
\text { Sedimentation } \\
\text { Rate }\end{array}$ & $\begin{array}{l}\text { If raised could indicate organic cause for } \\
\text { weight loss or an intercurrent bacterial } \\
\text { infection }\end{array}$ & \\
\hline Blood glucose & Low (acute starvation) & Hypoglycaemia \\
\hline $\begin{array}{l}\text { Thyroid Function } \\
\text { Tests }\end{array}$ & $\begin{array}{l}\text { To rule out hyperthyroid as a cause of } \\
\text { weight loss }\end{array}$ & \\
\hline ECG & $\begin{array}{l}\text { Features of electrolyte disturbance } \\
\text { Prolonged QTc } \\
\text { Sinus bradycardia }\end{array}$ & $\begin{array}{l}\text { Cardiac arrhythmia } \\
\text { QTc }>450 \mathrm{~ms}\end{array}$ \\
\hline Vitamins B \& D & May be low & \\
\hline
\end{tabular}

*Investigations are often normal, even in acutely unwell patients.

Tables are adapted from the following sources:

Hay, P., et al., Royal Australian and New Zealand College of Psychiatrists clinical practice guidelines for the treatment of eating disorders. Aust N Z J Psychiatry, 2014. 48(11): p. 977-1008.

NICE Clinical Knowledge Summaries Eating Disorders Revised October 2014. Last accessed October 2016.

Psychiatrists, R.C.o. Junior MARSIPAN: Management of Really Sick Patients under 18 with Anorexia Nervosa (CR168). 2012

Zipfel, S., et al., Anorexia nervosa: aetiology, assessment, and treatment. Lancet Psychiatry, 2015. 2(12): p. 1099-111 
Clinical consequences/comorbidities (diagram)

Labels around a diagram of a body (below) as follows:

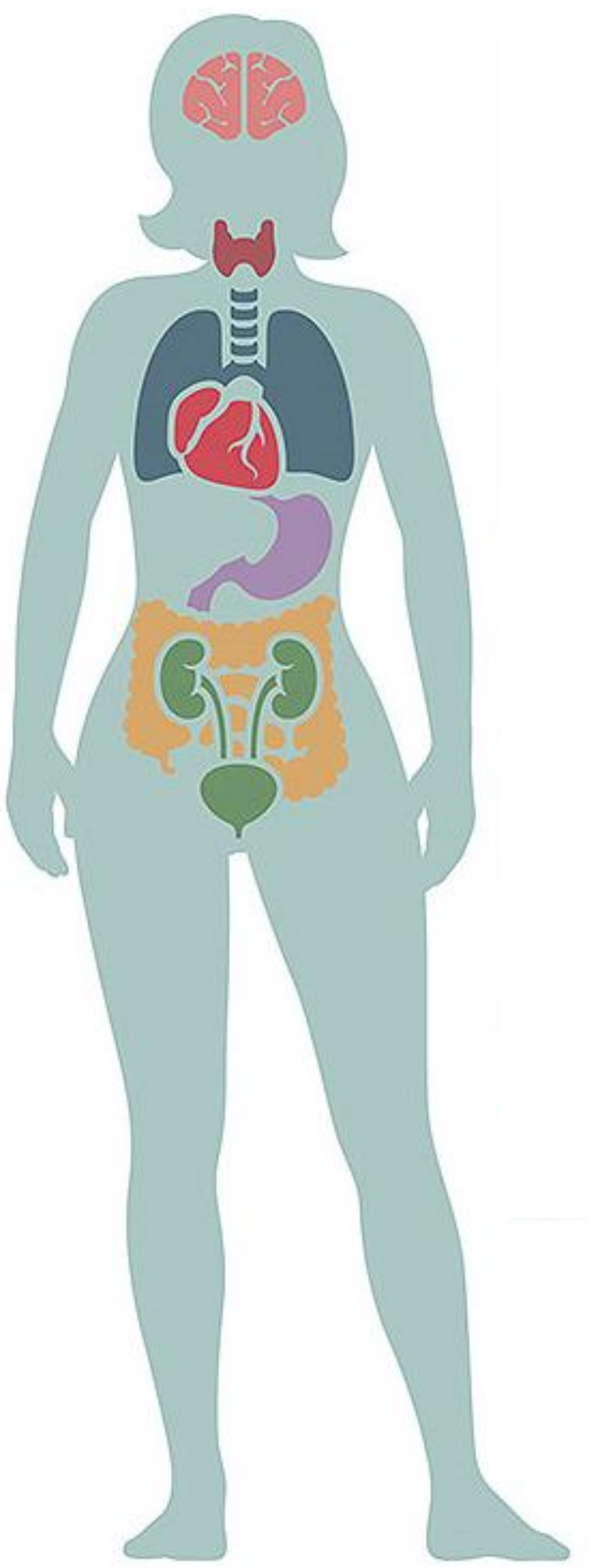

Mind/brain 
Depression

OCD

Anxiety

Self harm/suicide

Skin

Pressure sores in underweight

Bones

Osteoporosis/osteopaenia

Teeth

Dental erosion (advise do not brush teeth after vomiting; rinse mouth with water)

Fertility

Rates of unplanned pregnancy are higher; overall fertility does not seem to be lower

Higher rates of preterm birth and low birth weight infants

Cardiovascular

Arrhythmias

Heart block

Risk of cardiac arrest

Gastrointestinal

Gastro-oesophageal reflux (assoc. vomiting)

Acute gastric dilatation (rare; secondary to binges or excessive refeeding)

Haematology

Anaemia

Leucopaenia

Thrombocytopaenia

Biochemical

Raised cholesterol

Hypophosphataemia 
Dehydration (reduced fluid intake; extreme purging)

Electrolyte imbalances (secondary to laxative use or vomiting)

(rarely) Hypoglycaemia

1. SUSS Test

(Taken from http://www.rcpsych.ac.uk/pdf/CR189 a.pdf)

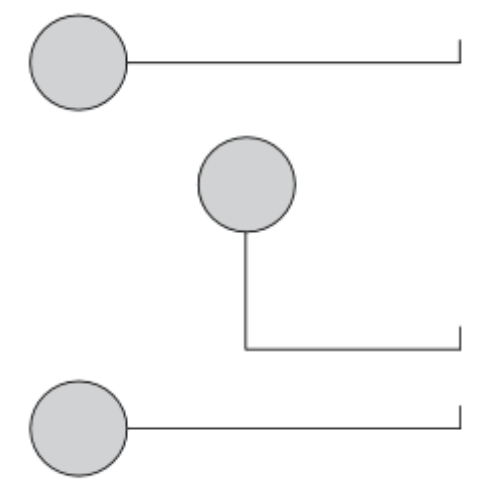

1. Sit-up: patient lies down flat on the floor and sits up without, if possible, using their hands.
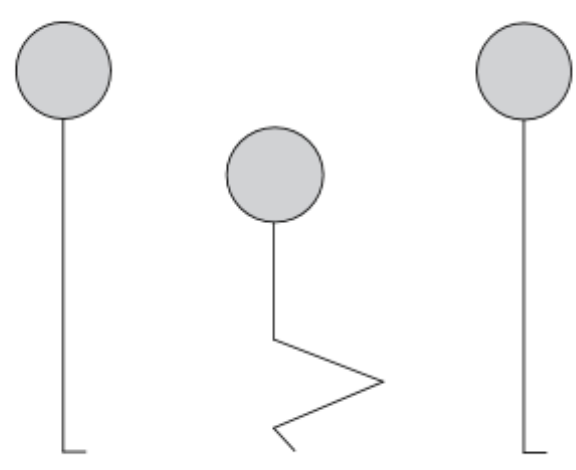

2. Squat-Stand: patient squats down and rises without, if possible, using their hands.

\author{
Scoring (for Sit-up and Squat-Stand tests separately) \\ 0 : Unable \\ 1: Able only using hands to help \\ 2: Able with noticeable difficulty \\ 3: Able with no difficulty
}

Fig. 1 The SUSS (Sit up-Squat-Stand test). From Robinson (2012).

Competing interest statement: We have read and understood the BMJ Group policy on declaration of interests and declare the following interests: none.

Copyright Statement: The Corresponding Author has the right to grant on behalf of all authors and does grant on behalf of all authors, an exclusive licence (or non exclusive for government employees) on a worldwide basis to the BMJ Publishing Group Ltd to permit this article (if accepted) to be published in BMJ editions and any other BMJPGL products and sub-licenses such use and exploit all subsidiary rights, as set out in our licence (bmj.com/advice/copyright.shtml).

CONTRIBUTORSHIP STATEMENT AND GUARANTOR: All authors contributed to the planning, conduct, and reporting of the work described in the article; HB wrote the first draft; $\mathrm{HB}$ \& MF are responsible for the overall content as guarantors; a recovered patient, and the parents of two patients, who wished to remain anonymous, reviewed a draft of the article and made several valuable contributions to its content. 
References

1. Association AP. Diagnostic and Statistical Manual of Mental Disorders. 5th edition ed. Arlington, VA: American Psychiatric Publishing, 2013.

2. WHO. ICD-11 Beta Draft (Foundation). Secondary ICD-11 Beta Draft (Foundation). http://apps.who.int/classifications/icd11/browse/f/en.

3. Arcelus J, Mitchell AJ, Wales J, et al. Mortality rates in patients with anorexia nervosa and other eating disorders. A meta-analysis of 36 studies. Arch Gen Psychiatry 2011;68(7):724-31.

4. Smink FR, van Hoeken D, Oldehinkel AJ, et al. Prevalence and severity of DSM-5 eating disorders in a community cohort of adolescents. The International journal of eating disorders 2014;47(6):610-9.

5. Micali N, Hagberg KW, Petersen I, et al. The incidence of eating disorders in the UK in 2000-2009: findings from the General Practice Research Database. BMJ Open 2013;3(5).

6. Whiteford HA, Degenhardt L, Rehm J, et al. Global burden of disease attributable to mental and substance use disorders: findings from the Global Burden of Disease Study 2010. Lancet 2013;382(9904):1575-86.

7. Swanson SA, Crow SJ, Le Grange D, et al. Prevalence and correlates of eating disorders in adolescents. Results from the national comorbidity survey replication adolescent supplement. Arch Gen Psychiatry 2011;68(7):714-23.

8. Davies SC. Annual Report of the Chief Medical Officer, 2014, The Health of the 51\%: Women. London: Dept of Health, 2015.

9. Treasure J, Russell G. The case for early intervention in anorexia nervosa: theoretical exploration of maintaining factors. Br J Psychiatry 2011;199(1):5-7.

10. Hay PJ, Touyz S, Sud R. Treatment for severe and enduring anorexia nervosa: a review. The Australian and New Zealand journal of psychiatry 2012;46(12):1136-44.

11. NICE. Eating disorders: recognition and treatment (NG69). In: Excellence NIfHaC, ed., 2017.

12. Fernandez-Aranda F, Pinheiro AP, Tozzi F, et al. Symptom profile of major depressive disorder in women with eating disorders. The Australian and New Zealand journal of psychiatry 2007;41(1):24-31.

13. Welch E, Jangmo A, Thornton LM, et al. Treatment-seeking patients with binge-eating disorder in the Swedish national registers: clinical course and psychiatric comorbidity. BMC psychiatry 2016;16:163.

14. Swinbourne JM, Touyz SW. The co-morbidity of eating disorders and anxiety disorders: a review. European eating disorders review : the journal of the Eating Disorders Association 2007;15(4):253-74.

15. Salbach-Andrae H, Lenz K, Simmendinger N, et al. Psychiatric comorbidities among female adolescents with anorexia nervosa. Child psychiatry and human development 2008;39(3):261-72.

16. Halmi KA, Sunday SR, Klump KL, et al. Obsessions and compulsions in anorexia nervosa subtypes. The International journal of eating disorders 2003;33(3):308-19.

17. Raevuori A, Haukka J, Vaarala $O$, et al. The increased risk for autoimmune diseases in patients with eating disorders. PloS one 2014;9(8):e104845.

18. Schmidt U, Treasure J. Anorexia nervosa: valued and visible. A cognitive-interpersonal maintenance model and its implications for research and practice. Br J Clin Psychol 2006;45(Pt 3):343-66.

19. Zipfel S, Giel KE, Bulik CM, et al. Anorexia nervosa: aetiology, assessment, and treatment. The lancet psychiatry 2015;2(12):1099-111.

20. Boghi A, Sterpone S, Sales S, et al. In vivo evidence of global and focal brain alterations in anorexia nervosa. Psychiatry research 2011;192(3):154-9. 
21. Psychiatrists RCo. Junior MARSIPAN: Management of Really Sick Patients under 18 with Anorexia Nervosa (CR168). 2012.

22. Hay P, Chinn D, Forbes D, et al. Royal Australian and New Zealand College of Psychiatrists clinical practice guidelines for the treatment of eating disorders. The Australian and New Zealand journal of psychiatry 2014;48(11):977-1008.

23. Facchini M, Sala L, Malfatto $G$, et al. Low-K+ dependent QT prolongation and risk for ventricular arrhythmia in anorexia nervosa. Int J Cardiol 2006;106(2):170-6.

24. Golden NH. Eating disorders in adolescence: what is the role of hormone replacement therapy? Curr Opin Obstet Gynecol 2007;19(5):434-9.

25. Singhal V, Misra M, Klibanski A. Endocrinology of anorexia nervosa in young people: recent insights. Curr Opin Endocrinol Diabetes Obes 2014;21(1):64-70.

26. Solmi M, Veronese N, Correll CU, et al. Bone mineral density, osteoporosis, and fractures among people with eating disorders: a systematic review and meta-analysis. Acta Psychiatr Scand 2016;133(5):341-51.

27. Steinhausen HC. The outcome of anorexia nervosa in the 20th century. Am J Psychiatry 2002;159(8):1284-93.

28. Lock JLG, D. Treatment Manual for Anorexia Nervosa: A Family-Based Approach. 2nd ed: Guilford Press, 2015.

29. Lock J. An Update on Evidence-Based Psychosocial Treatments for Eating Disorders in Children and Adolescents. Journal of clinical child and adolescent psychology : the official journal for the Society of Clinical Child and Adolescent Psychology, American Psychological Association, Division 53 2015;44(5):707-21.

30. le Grange D, Crosby RD, Rathouz PJ, et al. A randomized controlled comparison of family-based treatment and supportive psychotherapy for adolescent bulimia nervosa. Arch Gen Psychiatry 2007;64(9):1049-56.

31. Fairburn CG, Cooper Z, Doll HA, et al. Transdiagnostic cognitive-behavioral therapy for patients with eating disorders: a two-site trial with 60-week follow-up. Am J Psychiatry 2009;166(3):311-9.

32. Keel PK, Haedt A. Evidence-based psychosocial treatments for eating problems and eating disorders. Journal of clinical child and adolescent psychology : the official journal for the Society of Clinical Child and Adolescent Psychology, American Psychological Association, Division 53 2008;37(1):39-61.

33. Schmidt $U$, Lee $S$, Beecham J, et al. A randomized controlled trial of family therapy and cognitive behavior therapy guided self-care for adolescents with bulimia nervosa and related disorders. Am J Psychiatry 2007;164(4):591-8.

34. de Vos J, Houtzager L, Katsaragaki G, et al. Meta analysis on the efficacy of pharmacotherapy versus placebo on anorexia nervosa. Journal of eating disorders 2014;2(1):27.

35. Dold M, Aigner M, Klabunde M, et al. Second-Generation Antipsychotic Drugs in Anorexia Nervosa: A Meta-Analysis of Randomized Controlled Trials. Psychother Psychosom 2015;84(2):110-16.

36. Wu CS, Tsai YT, Tsai HJ. Antipsychotic drugs and the risk of ventricular arrhythmia and/or sudden cardiac death: a nation-wide case-crossover study. J Am Heart Assoc 2015;4(2).

37. Bacaltchuk J, Hay P. Antidepressants versus placebo for people with bulimia nervosa. Cochrane Database Syst Rev 2003(4):CD003391.

38. Bacaltchuk J, Hay P, Trefiglio R. Antidepressants versus psychological treatments and their combination for bulimia nervosa. Cochrane Database Syst Rev 2001(4):CD003385.

39. Mitchell JE, Roerig J, Steffen K. Biological therapies for eating disorders. The International journal of eating disorders 2013;46(5):470-7.

40. Fitzpatrick KK, Lock J. Anorexia nervosa. BMJ Clin Evid 2011;2011. 
41. Health NCCfM. Eating Disorders: Core interventions in the treatment and management of anorexia nervosa, bulimia nervosa and related eating disorders: National Institute for Clinical Excellence, 2004.

42. O'Connor G, Nicholls D, Hudson L, et al. Refeeding Low Weight Hospitalized Adolescents With Anorexia Nervosa: A Multicenter Randomized Controlled Trial. Nutr Clin Pract 2016;31(5):681-9.

43. House J, Schmidt U, Craig M, et al. Comparison of specialist and nonspecialist care pathways for adolescents with anorexia nervosa and related eating disorders. The International journal of eating disorders 2012;45(8):949-56.

44. Madden S, Hay P, Touyz S. Systematic review of evidence for different treatment settings in anorexia nervosa. World J Psychiatry 2015;5(1):147-53.

45. NICE. NICE guideline [NG43] Transition from children's to adults' services for young people using health or social care services, 2016.

46. Bailey AP, Parker AG, Colautti LA, et al. Mapping the evidence for the prevention and treatment of eating disorders in young people. Journal of eating disorders 2014;2:5.

47. Wilksch SM, Paxton SJ, Byrne SM, et al. Prevention Across the Spectrum: a randomized controlled trial of three programs to reduce risk factors for both eating disorders and obesity. Psychol Med 2015;45(9):1811-23.

48. van Furth EF, van der Meer A, Cowan K. Top 10 research priorities for eating disorders. The lancet psychiatry 2016;3(8):706-7.

49. England N. Access and waiting times standard for children and young people with an eating disorder: National Collaborating Centre for Mental Health, 2015. 